\title{
Erratum to: Stability of economy of the organizations under the conditions of modern economic environment
}

\author{
S.Yu. Ilyin ${ }^{1}$, Y.V. Lebedeva ${ }^{2}$, A.A. Sigankov ${ }^{3}$, O.N. Beketova ${ }^{3}$, I.V. Shatskaya ${ }^{3}$ and A.L. Frolov ${ }^{3}$ \\ ${ }^{1}$ Financial University under the Government of the Russian Federation, Leningradsky prospect, 51/1, \\ 125993, Russian Federation \\ ${ }^{2}$ Moscow Academy of Finance and Law (MFUA) \\ ${ }^{3}$ MIREA - Russian technological university, Prospekt Vernadskogo, 78, 119454 Moscow, Russia
}

Original article: E3S Web of Conferences 291, 07002 (2021),

https://doi.org/10.1051/e3sconf/202129107002

The authors and the authors affiliations of the article should be replaced. The reason why S. Yu. Ilyin was added to the list of authors comes from an error at submission. Indeed, his name was forgotten from the original list. 